\title{
Hydrogen Absorption Behavior and Absorbed Hydrogen Trapping Sites in Rolling Contact Fatigue
}

\author{
Miyuri KAMEYA, ${ }^{1{ }^{1 *}}$ Toshiyuki MANABE, ${ }^{1)}$ Naoki MATSUI, ${ }^{1)}$ Shingo YAMASAK ${ }^{21}$ and Tomohiko OMURA ${ }^{1)}$ \\ 1) Steel Research Laboratories, Nippon Steel Corporation, 20-1 Shintomi, Futtsu-Shi, Chiba, 293-8511 Japan. \\ 2) Advanced Technology Research Laboratories, Nippon Steel Corporation, 20-1 Shintomi, Futtsu-Shi, Chiba, $293-8511$ Japan.
}

(Received on August 6, 2020; accepted on October 21, 2020; J-STAGE Advance published date:

December 19, 2020)

\begin{abstract}
Hydrogen absorption behavior and microstructural change of carburized JIS SCr420 steels containing different amounts of retained austenite in rolling contact fatigue were investigated. The thermal desorption analysis confirmed hydrogen desorption at the second-peak between 423 and $623 \mathrm{~K}$ after rolling contact fatigue. The hydrogen concentration at the second-peak increased with number of cycles in the rolling contact. This increment was larger when using the steel with higher amount of retained austenite before the fatigue test. It was still large even when the amount of martensitic transformation from retained austenite under cyclic stress to introduce dislocation with trapping capacity was small. The activation energies of desorption for the second-peak hydrogen were calculated to be $50.6 \mathrm{~kJ} \cdot \mathrm{mol}^{-1}$ for the steel with $10.4 \%$ retained austenite and $55.8 \mathrm{~kJ} \cdot \mathrm{mol}^{-1}$ for the steel with $4.9 \%$ retained austenite. The activation energies of cathodically charged $0.8 \% \mathrm{C}$ steels with $10.9 \%$ and $6.0 \%$ retained austenite, simulating carburized layer before the test, were 36.2 and $42.2 \mathrm{~kJ} \cdot \mathrm{mol}^{-1}$, respectively. This means that the activation energy of hydrogen desorption increased during rolling contact. The absorbed hydrogen during the rolling contact fatigue was likely trapped in more stable trapping sites related to the retained austenite which were formed under cyclic stress.
\end{abstract}

KEY WORDS: hydrogen embrittlement; rolling contact fatigue; martensitic steel; retained austenite; thermal desorption analysis.

\section{Introduction}

Bearings are used as important component parts in a wide variety of applications such as automobiles, railroads, and industrial machines. Particularly in recent years, demand has risen for higher-strength steels for bearings used in the undercarriages and drive units of automobiles to satisfy requirements for smaller and lighter vehicles. The damage types in the rolling contact fatigue of bearings can mainly be divided into the surface-origin type and the internal-origin type. ${ }^{1)}$ Surface-origin flaking is caused by contaminations such as metal powders in lubricating oil and by contact with metal. Internal-origin flaking, on the other hand, results from the presence of nonmetallic inclusions like oxides and from microstructural changes during rolling contact fatigue in regions where the shear stress is high beneath rolling contact surface. Bearings have a problem of crack initiation and short life flaking caused by white etching area (WEA) alteration, a microstructural change that occurs during rolling contact fatigue. ${ }^{2-5)}$ WEA is regarded as a microstructure

\footnotetext{
* Corresponding author: E-mail: kameya.rr7.miyuri@jp.nipponsteel.com
}

generated due to dislocation rearrangement and dislocation cell formation during cyclic stressing under rolling contact fatigue. ${ }^{6,7)}$ Because the WEA is simulated in a rolling contact fatigue test with hydrogen-charged steel specimens, ${ }^{8,9)}$ it is considered as a phenomenon related to hydrogen in steel.

To improve the rolling contact fatigue life of bearings, it is important to understand the formation behavior of the WEA responsible for short life flaking. As hydrogen is considered to be related to the formation of WEA, ${ }^{10-12)}$ it is also important to understand the behavior of hydrogen absorption into steels and the trapping sites of absorbed hydrogen during rolling contact fatigue. However, there have been few detailed studies on hydrogen absorption behavior of bearings affected by rolling contact fatigue.

In this study, the transitions during fatigue test in hydrogen absorption behavior and microstructure before the formation of WEA were investigated by using a two-roller rolling contact fatigue tester for various numbers of cycles of rolling contact fatigue. To investigate the possibility of retained austenite being the trapping sites for absorbed hydrogen, specimens with different volume fraction of retained austenite were prepared by applying subzero treat- 
ment, and the effect of the volume fraction of retained austenite on hydrogen absorption behavior was investigated.

\section{Experimental Method}

\subsection{Material}

Table 1 shows the chemical composition of the test steel. The test steel is JIS SCr420 which is the low-alloyed steel for machine structural use. The steel was vacuum melted, casted, and hot forged into $\varphi 35 \mathrm{~mm}$ round bars. From the $\varphi 35 \mathrm{~mm}$ round bars, $\varphi 26 \mathrm{~mm}$ roller specimens were prepared for the two-roller rolling contact fatigue test. The specimens were vacuum carburized at $1203 \mathrm{~K}$ and quenched in a $353 \mathrm{~K}$ oil tank. The depth of the hardened layer after carburizing was $1.4 \mathrm{~mm}$. The specimen A was tempered at $453 \mathrm{~K}$ after carburizing. The specimen $\mathrm{B}$ was subzero treated after carburizing to reduce the volume fraction of retained austenite and then tempered at $473 \mathrm{~K}$. Because the volume fraction of retained austenite which is softer than martensite was lower in the specimen B than the specimen $\mathrm{A}$, the specimen $\mathrm{B}$ was tempered at a higher temperature than the specimen A to achieve the same hardness as the specimen A.

\subsection{Rolling Contact Fatigue Test}

The rolling contact fatigue test was conducted using a two-rolling contact fatigue tester. The tester is schematically illustrated in Fig. 1. The small $\varphi 26 \mathrm{~mm}$ roller is the test roller and the large $\varphi 130 \mathrm{~mm}$ roller is the loading roller. The loading roller was made of JIS SUJ2 high-carbon chromiumbearing steel. The two-roller rolling contact fatigue test was

Table 1. Chemical composition of the test steel (mass\%).

\begin{tabular}{ccccccccc}
\hline & $\mathrm{C}$ & $\mathrm{Si}$ & $\mathrm{Mn}$ & $\mathrm{P}$ & $\mathrm{S}$ & $\mathrm{Cr}$ & $\mathrm{Al}$ & $\mathrm{N}$ \\
\hline $\mathrm{SCr} 420$ & 0.21 & 0.25 & 0.74 & 0.002 & 0.001 & 1.05 & 0.024 & 0.011 \\
\hline
\end{tabular}

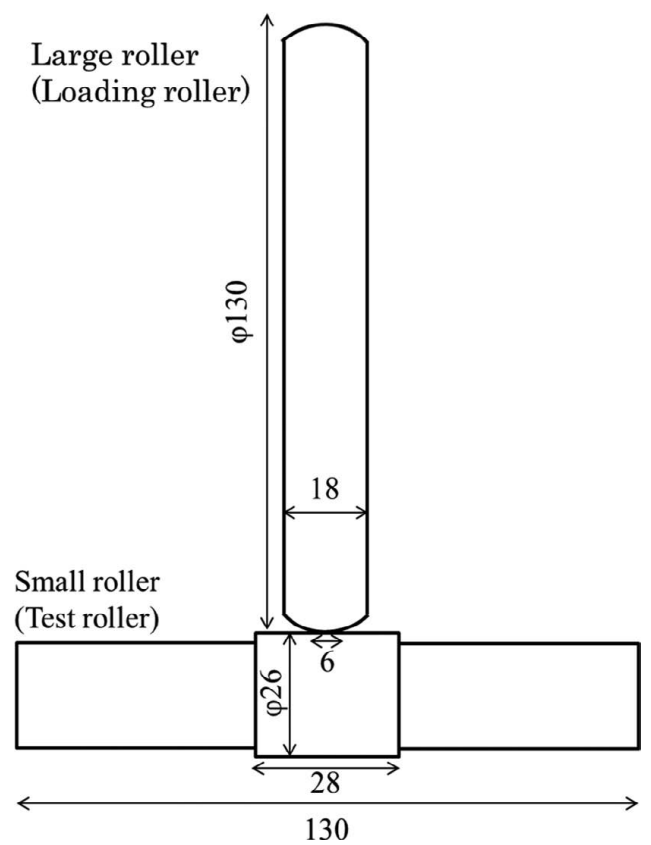

Fig. 1. Schematic illustration of two-roller rolling contact fatigue tester. conducted at a maximum Hertzian contact stress of 2700 $\mathrm{MPa}$, a slip rate of $-40 \%$, a small-roller rotation speed of $1500 \mathrm{rpm}$, and an oil temperature of $363 \mathrm{~K}$. The contact width between the small and large rollers was about $6 \mathrm{~mm}$. The number of cycles was varied between $5 \times 10^{5}$ and $2 \times$ $10^{7}$, and the test was finished before flaking occurred.

After the test, the small-roller specimens were subjected to microstructural analysis and hydrogen analysis. The specimens for hydrogen analysis were removed from the tester immediately after the test and were stored in liquid nitrogen to prevent desorption of the hydrogen until the hydrogen analysis.

\subsection{Microstructural Analysis}

The small-roller specimens before and after the tests were investigated for their hardness, microstructure, dislocation density, and volume fraction of retained austenite. The hardness was measured with a Vickers hardness tester at a load of $300 \mathrm{gf}$ at positions of 0.1 to $2.0 \mathrm{~mm}$ from the surface of carburized layer. The microstructures were observed with a scanning electron microscope (SEM) and a transmission electron microscope (TEM). The SEM and TEM specimens were prepared using electrolytic polishing. The dislocation density was calculated by using the modified WarrenAverbach method from the average contrast factor. ${ }^{13)}$ The average contrast factor was obtained using the WilliamsonHall method from the (110), (200) and (211) diffraction peaks of $\alpha$-Fe obtained with x-ray diffractometry. The SEM observations, TEM observations, and x-ray diffraction for the dislocation density calculation were conducted at a depth of $200 \mu \mathrm{m}$ from the surface of carburized layer in which near the depth of maximum shear stress under the test conditions.

The volume fraction of retained austenite was measured by X-ray diffractometry. The x-ray diffraction measurements were conducted at $0,0.1,0.2,0.3$, and $0.5 \mathrm{~mm}$ from the surface of carburized layer. The five-point average values were taken as the retained austenite volume fraction of the specimens.

\subsection{Hydrogen Analysis}

The hydrogen analysis was conducted with the thermal desorption analysis (TDA) method, using a gas chromatograph as the detection system. From the small rollers after the test, $\varphi 26 \times 5 \mathrm{~mm}$ L semicylindrical specimens containing the contact area with the large roller were cut out. These specimens were then rinsed in acetone, heated at a constant rate of $100 \mathrm{~K} \cdot \mathrm{h}^{-1}$ from room temperature to $873 \mathrm{~K}$, and analyzed for hydrogen once per $5 \mathrm{~min}$.

\section{Experimental Results}

\subsection{Microstructural Changes with Rolling Contact Fatigue}

Figure 2 shows the hardness profile of the carburized layer. The specimens A and B show almost the same hardness profiles as originally intended. Figure 3 shows the average volume fraction of retained austenite before the rolling contact fatigue test and after $5 \times 10^{5}, 9 \times 10^{6}$, and $2 \times 10^{7}$ test cycles. The volume fraction of retained austenite decreased with increasing number of cycles, probably because the martensite transformation of the retained aus- 
tenite proceeded under rolling contact stress. It was clarified that the specimen B with the smaller volume fraction of retained austenite before the fatigue test showed the smaller amount of retained austenite transformed to martensite.

Figure 4 shows SEM micrographs of the specimens $\mathrm{A}$ and $\mathrm{B}$ before the test. Each microstructure is mainly composed of martensite laths, with fine retained austenite confirmed to exist between the martensite laths. Figure 5 shows the TEM dislocation substructure of the specimen A before the test and after $2 \times 10^{7}$ test cycles. The dislocations before the test were high in density and uniformly distributed. After $2 \times 10^{7}$ test cycles, on the other hand, there were regions where the dislocations were distributed at high density as before the test and regions where dislocation cell structures were formed. The specimen B showed the same microstructural changes as the specimes A before and after the test. The dislocation density calculated from the $\mathrm{x}$-ray diffraction measurements was $1.7 \times 10^{16} \mathrm{~m}^{-2}$ and $9 \times 10^{15}$ $\mathrm{m}^{-2}$ for the specimen A before the test and after $2 \times 10^{7}$ test cycles, respectively, and was $1.5 \times 10^{16} \mathrm{~m}^{-2}$ and $7 \times 10^{15}$ $\mathrm{m}^{-2}$ for the specimen $\mathrm{B}$ before the test and after $2 \times 10^{7}$ test cycles, respectively. This clarified that the dislocation densities decreased during contact fatigue test in both specimens $\mathrm{A}$ and $\mathrm{B}$, and that the dislocation densities before and after

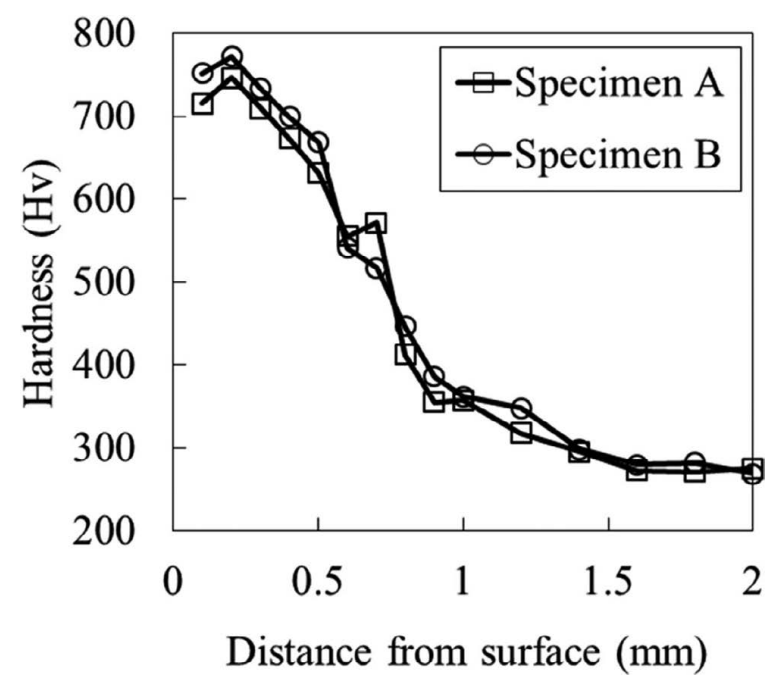

Fig. 2. Hardness profiles of the specimens A and B.

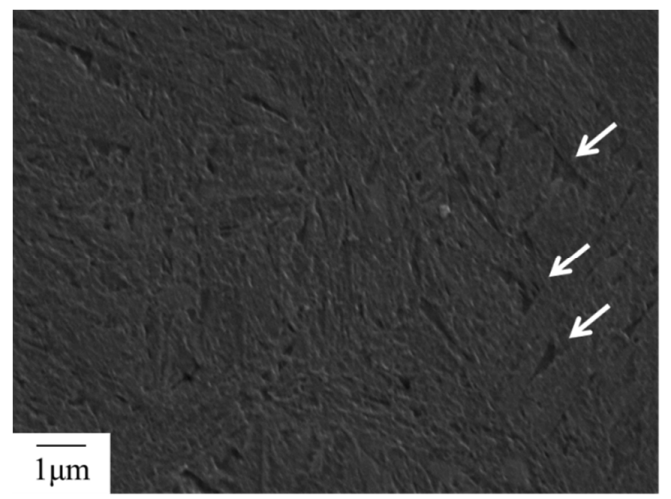

(a) Specimen A the test were almost the same in both specimens A and B.

\subsection{Hydrogen Absorption Behavior in Rolling Contact Fatigue Regions}

Figure 6 shows the hydrogen evolution-rate curves by TDA of the specimens A and B before the rolling contact fatigue test and after $9 \times 10^{6}$ and $2 \times 10^{7}$ test cycles. The desorption of hydrogen was confirmed to have occurred between 300 and $450 \mathrm{~K}$ and between 623 to $873 \mathrm{~K}$ before the test. After $9 \times 10^{6}$ and $2 \times 10^{7}$ test cycles, the desorption of hydrogen was confirmed to have occurred between 300 and $423 \mathrm{~K}$ and between 623 and $873 \mathrm{~K}$, and also between 423 and $623 \mathrm{~K}$. These hydrogen desorption peaks are respectively called the first, second, and third peaks in ascending order of hydrogen desorption temperature. It was confirmed that only the second peak increased with an increasing number of cycles in both specimens A and B. No changes were recognized in the first and third peaks with an increasing number of cycles. Figure 7 shows the relationship between the hydrogen concentration at the second peaks of the specimens $\mathrm{A}$ and $\mathrm{B}$ and the number of cycles in the rolling contact fatigue test. It was confirmed that the increment of the second-peak hydrogen concentration during the rolling contact fatigue test was higher in the

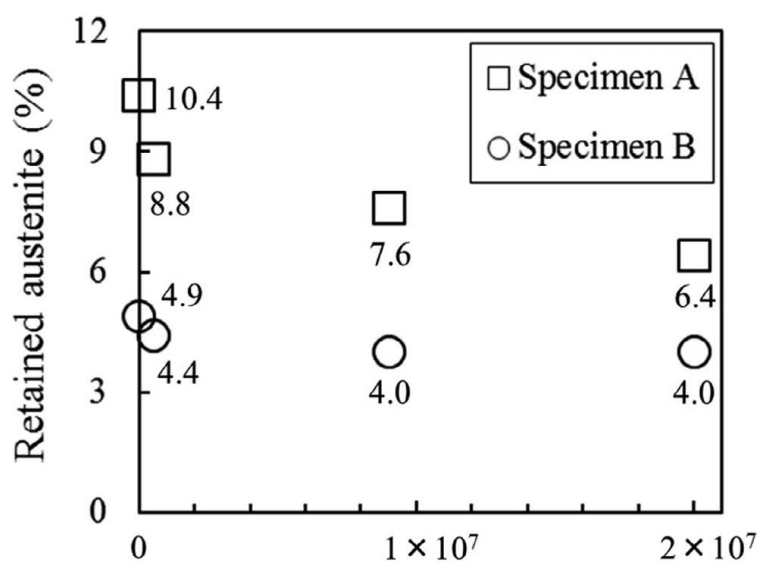

Number of cycles

Fig. 3. Change in volume fraction of retained austenite before and after the rolling contact fatigue test.

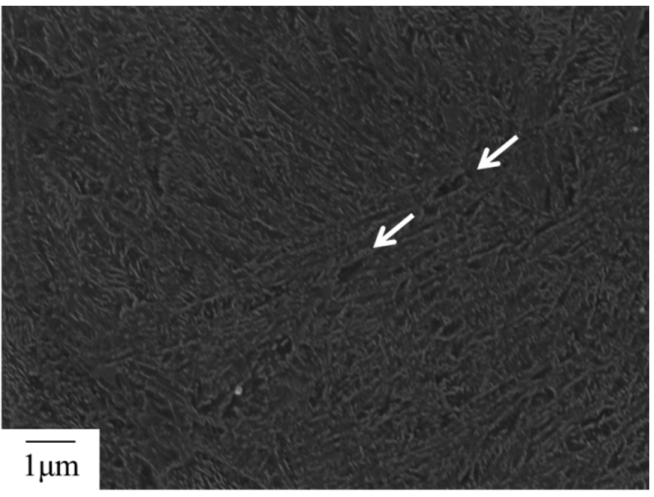

(b) Specimen B

Fig. 4. SEM micrographs before the rolling contact fatigue test. Arrows represent the regions where retained austenite existed. 


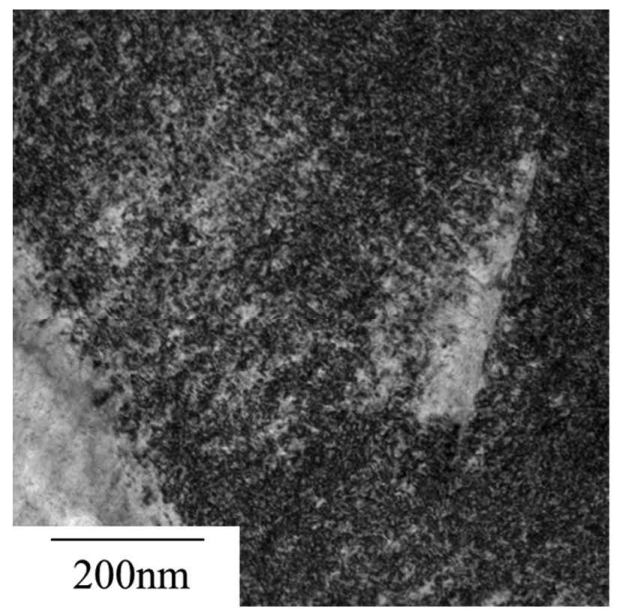

(a) Before test

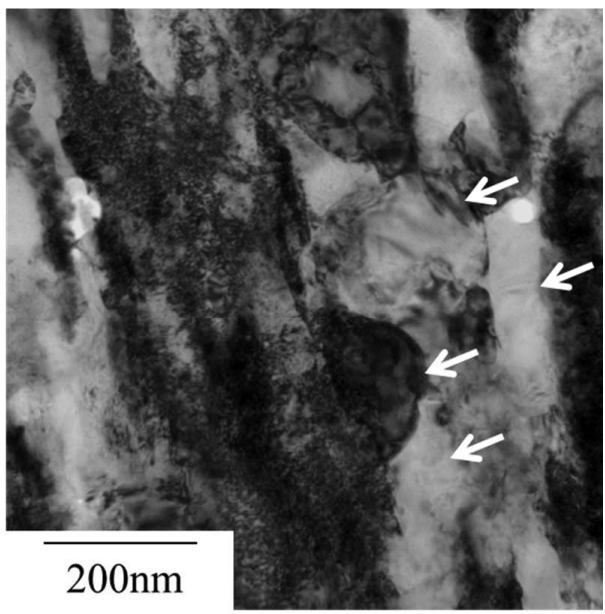

(b) After $2 \times 10^{7}$ cycles

Fig. 5. TEM micrographs of dislocation substructure in specimen A before the rolling contact fatigue test and after $2 \times 10^{7}$ test cycles. Arrows represent the regions where dislocation cells formed.

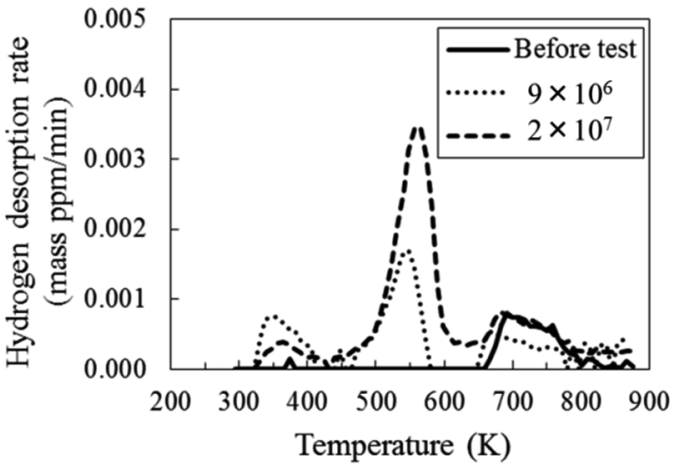

(a) Specimen A

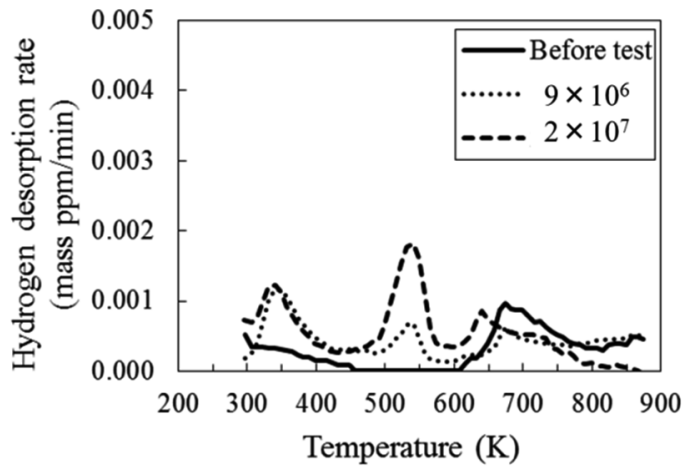

(b) Specimen B

Fig. 6. TDA profiles of hydrogen before and after the rolling contact fatigue test.

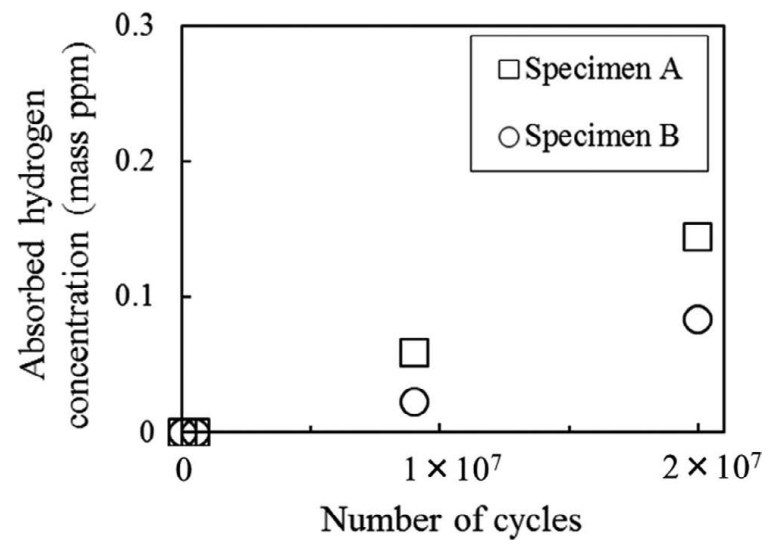

Fig. 7. Relationship between the absorbed hydrogen concentration at the second peaks and the number of cycles.

specimen A which is contained higher amount of retained austenite than the specimen B before the fatigue test.

Regarding the first-peak hydrogen, Takai et al. ${ }^{14)}$ speculate that this is the hydrogen trapped in atomic vacancy and dislocation stress fields according to the results of their investigation using wire-drawn eutectoid steel. In the pres- ent experiment, dislocations regarded as trapping sites for the first-peak hydrogen exist from the contact surface layer to the bulk of the specimen. The hydrogen concentration of the first peak indicates the total amount of hydrogen present from the surface layer to the bulk of the specimens. Accordingly, the first-peak hydrogen does not reflect only the effect of rolling contact. As the hydrogen content only at the second peak increases with an increasing number of cycles in the rolling contact fatigue test, it can be said that the second-peak hydrogen was absorbed into the specimens due to rolling contact fatigue. It has been reported that dislocation cores ${ }^{15)}$ and retained austenite ${ }^{16)}$ can be considered as trapping sites for the hydrogen desorbed at temperature around 423 to $623 \mathrm{~K}$ in TDA.

To investigate the depth from the surface of specimen to which absorbed hydrogen exists, the test rollers of the specimen A $(\varphi 26 \mathrm{~mm})$ were thinned to $\varphi 24.64 \mathrm{~mm}(0.68$ $\mathrm{mm}$ reduction in radius) and to $\varphi 23.0 \mathrm{~mm}(1.5 \mathrm{~mm}$ reduction in radius) after $9 \times 10^{6}$ cycles of the test. Specimens were thinned by grinding and electrolytic polishing. The second-peak hydrogen concentration was analyzed for each specimen and was normalized with the data of $\varphi 26 \mathrm{~mm}$ specimen (without thinning). Figure 8 shows the relation- 


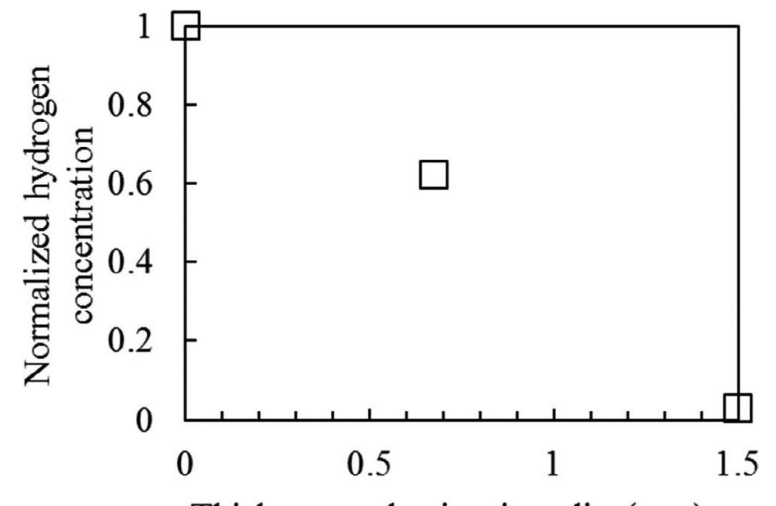

Thickness reduction in radius $(\mathrm{mm})$

Fig. 8. Relationship between the normalized hydrogen concentration of the specimen A and the thickness reduction in radius.

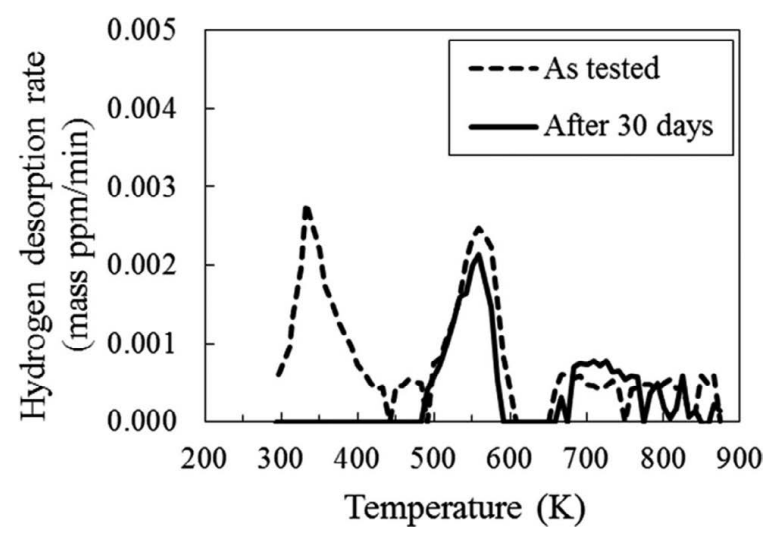

Fig. 9. TDA profiles of hydrogen of specimen A preserved at room temperature for 30 days after the rolling contact fatigue test.

ship between the normalized hydrogen concentration and the thickness reduction in radius. The normalized hydrogen concentration decreased as the thickness reduction in radius increased. Low levels of hydrogen were present in the specimen thinned by $1.5 \mathrm{~mm}$ in radius. This clarified that absorbed hydrogen was trapped to $1.5 \mathrm{~mm}$ depth beneath the rolling-contact surface under the rolling-contact fatigue test conditions of the present study.

Figure 9 shows the hydrogen evolution rate curves of the specimen A preserved at room temperature for 30 days after the fatigue test to investigate the stability of the secondpeak hydrogen. The first-peak hydrogen disappeared during 30 days after the fatigue test. On the other hand, it was confirmed that the height of the second-peak hydrogen did not change significantly from the value taken immediately after the test.

\section{Discussion}

\subsection{Microstructural Changes with Rolling Contact Fatigue}

From both results of TEM observations and dislocation density measurements, it is considered that cyclic stressing under rolling contact fatigue caused the rearrangement of dislocations and the formation of dislocation cells, ${ }^{17)}$ resulting in a decrease of the dislocation density.

As shown in Fig. 3, the reduction in the volume fraction of retained austenite was greater in the specimen A, which contained the higher volume fraction of retained austenite before the fatigue test. This mechanism is considered to be as follows: The specimen A contains larger volume fraction of thermally unstable austenite than the specimen $\mathrm{B}$ because the subzero treatment transformed the thermally unstable austenite to martensite in the specimen B. Assuming the similarity between thermal stability and stability against plastic deformation of retained austenite, thermally unstable retained austenite is easily transformed to martensite by plastic deformation associated with rolling contact fatigue. ${ }^{18)}$ It is therefore considered that retained austenite significantly decreased as the number of cycles of fatigue test increased in the specimen A than the specimen B.

\subsection{Hydrogen Trap Site in Rolling Contact Fatigue}

4.2.1. Dislocation Core

The binding energy between the dislocation cores and hydrogen is $42 \mathrm{~kJ} \cdot \mathrm{mol}^{-1},{ }^{19)}$ and the binding energy between the dislocation cores and carbon is $63.6 \mathrm{~kJ} \cdot \mathrm{mol}^{-1} \cdot{ }^{20)}$ Carbon atoms are consequently trapped by dislocations preferentially than hydrogen atoms. In the microstructure before rolling contact fatigue, it is considered that the hydrogen trapping capacity of the dislocation cores is expected to be low, since carbon atoms segregate to dislocations because of the tempering at $473 \mathrm{~K}$ after carburization at which carbon diffuses but precipitate of carbide are less. On the other hand, it is expected that cyclic stressing during rolling contact fatigue causes the martensitic transformation of retained austenite and introduces free dislocations without the segregation of carbon atoms at which hydrogen atoms are capably trapped. It is therefore considered that, in the case that the hydrogen trapping sites for the second-peak hydrogen are the dislocation cores, the dislocations which cause hydrogen trapping are considered to be introduced by martensite transformation of the retained austenite during rolling contact fatigue. However, the results of Figs. 3 and 7 confirmed an increase in the absorbed hydrogen concentration at the second peak, although the volume fraction of retained austenite did not change significantly, from $9 \times 10^{6}$ cycles to $2 \times 10^{7}$ test cycles of the specimen B. Furthermore, it has been reported that the hydrogen trapped by dislocation cores decreased during 7 days preservation of specimens at room temperature, because of the site competition with carbon atoms of which binding energy with dislocation is higher than that of hydrogen atoms. ${ }^{15}$ ) In the present study, it was expected that if the trapping sites of the second-peak hydrogen were dislocation cores, the hydrogen in the dislocation cores would be replaced by carbon due to the site competition effect and would desorb from the specimens as the specimens were preserved at room temperature. However, the results in Fig. 9 confirmed that the absorbed hydrogen concentration at the second peak did not change significantly when the rolling contact fatigue test specimens were preserved at room temperature for 30 days. These results suggest that the dislocation cores may not be the main trapping sites for the second-peak hydrogen.

\subsubsection{Retained Austenite}

The second-peak hydrogen concentration depended on the volume fraction of retained austenite before the fatigue 
test, and it was considered that the dislocation cores would not work as the main trapping sites for the second-peak hydrogen. From these results, it is considered that the main trapping sites of hydrogen absorbed during the fatigue test were related to retained austenite. The hydrogen trapping sites related to retained austenite are considered to be the bulk of retained austenite or the interface between martensite and retained austenite.

The reason why the absorbed hydrogen concentration increases despite the decrease in the volume fraction of retained austenite with an increasing number of fatigue cycles is possibly due to the extremely high hydrogen solubility in FCC metals than that in BCC metals. Takai et $a l^{21)}$ investigated the hydrogen storage properties of FCC metals by using Inconel 625 electrochemical charged with hydrogen. They reported that its hydrogen storage capacity was 230 mass ppm. Assuming that the hydrogen capacity of retained austenite, an FCC structure, is about the same as that of Inconel 625, the allowable amount of hydrogen in the specimens with the $4 \%$ volume fraction of retained austenite, that is the amount of the retained austenite in the specimen B after $2 \times 10^{7}$ test cycles, is calculated to be approximately 9.2 mass ppm. The absorbed hydrogen in the rolling-contact fatigue test of the present study was trapped the region from the rolling-contact surface to the depth of $1.5 \mathrm{~mm}$ as shown in Fig. 8. Assuming that the absorbed hydrogen concentration of $0.08 \mathrm{ppm}$ for the specimen B after $2 \times 10^{7}$ fatigue cycle test exist the surface region of $1.5 \mathrm{~mm}$ depth, it is possibly re-calculated as $0.38 \mathrm{ppm}$, in terms of the steel weight to the surface region. This suggests that the hydrogen trapping capacity of retained austenite is significantly high with respect to the absorbed hydrogen amount in the rolling contact fatigue test of the present study. Accordingly, the absorbed hydrogen detected as the second-peak in the TDA profiles is not sufficient in the trapping sites originating from retained austenite at the early stage of fatigue cycles, and increases with an increasing number of cycles. Although the volume fraction of retained austenite decreases as the number of fatigue cycles increases, it is considered that stable retained austenite that has not transformed in rolling contact fatigue contributed as hydrogen trapping sites. Figure 10 shows the schematic illustrations of the hydrogen trapping behavior by retained austenite in rolling contact fatigue.

\subsubsection{Activation Energy of Hydrogen Trap}

To clarify the trapping sites for the second-peak hydrogen from the activation energy of hydrogen desorption Ea, Ea was calculated from the heating rate dependence of the hydrogen desorption peak temperature in TDA profiles by the Choo-Lee method ${ }^{22)}$ expressed in Eq. (1).

$$
\frac{\partial \ln \left(\Phi / T_{c}^{2}\right)}{\partial T_{c}^{-1}}=-\frac{E_{a}}{R}
$$

Where $\Phi$ is the heating rate in TDA $\left(\mathrm{K} \cdot \mathrm{s}^{-1}\right), \mathrm{T}_{\mathrm{C}}$ is the peak temperature $(\mathrm{K}), \mathrm{R}$ is the gas constant $\left(\mathrm{J} \cdot \mathrm{K}^{-1} \cdot \mathrm{mol}^{-1}\right)$, and $\mathrm{Ea}$ is the activation energy $\left(\mathrm{J} \cdot \mathrm{mol}^{-1}\right)$. For this purpose, the specimens of $2 \times 10^{7}$ fatigue test cycles were adopted and the heating rate $\Phi$ was varied 0.014 to $0.056 \mathrm{~K} \cdot \mathrm{s}^{-1}$.

The TDA profiles of hydrogen measured by changing the heating rate are shown in Fig. 11 and the relationship between $\ln \left(\Phi / \mathrm{T}_{\mathrm{C}}{ }^{2}\right)$ and $\mathrm{T}_{\mathrm{C}}{ }^{-1}$ is shown in Fig. 12. The Ea after the rolling contact fatigue test was $50.6 \mathrm{~kJ} \cdot \mathrm{mol}^{-1}$ for the specimen A and $55.8 \mathrm{~kJ} \cdot \mathrm{mol}^{-1}$ for the specimen B. These Ea values of the specimens $\mathrm{A}$ and $\mathrm{B}$ are higher than 30 to $46 \mathrm{~kJ} \cdot \mathrm{mol}^{-1}$ reported by Sekine et al. $^{23)}$ for a dualphase steel composed of martensite and 10\% retained austenite and $46 \mathrm{~kJ} \cdot \mathrm{mol}^{-1}$ reported by Takai et al. ${ }^{21)}$ for Inconel 625 , an FCC metal. If the hydrogen trapping sites of the specimens A and B are austenite retained without transforming, the reason why the Ea is higher for the specimen $\mathrm{B}$ is considered to be the difference in hydrogen trapping energy between the bulk of retained austenite and the ferrite/austenite interface, or the difference in the size of the retained austenite. The hydrogen trapping energy by the dislocation cores is reported to be $42 \mathrm{~kJ} \cdot \mathrm{mol}^{-119)}$ and is lower than the Ea of the specimens A and B after the test. It was therefore considered that the dislocation cores are not considered to be the main trapping sites for the absorbed hydrogen.

To investigate the Ea of the specimens $\mathrm{A}$ and $\mathrm{B}$ before the rolling contact fatigue test, non-subzero-treated and subzero-treated specimen of $0.8 \% \mathrm{C}$ steel $(0.78 \mathrm{C}-0.26 \mathrm{Si}$ $0.73 \mathrm{Mn}-0.99 \mathrm{Cr}-0.028 \mathrm{Al}$ in mass $\%$ ) which simulated the carburized surface layers were prepared by the same method with the specimens $\mathrm{A}$ and $\mathrm{B}$. The dimension of specimen was $20 \mathrm{~mm}$ in length, $15 \mathrm{~mm}$ in width and $0.5 \mathrm{~mm}$ in thick-

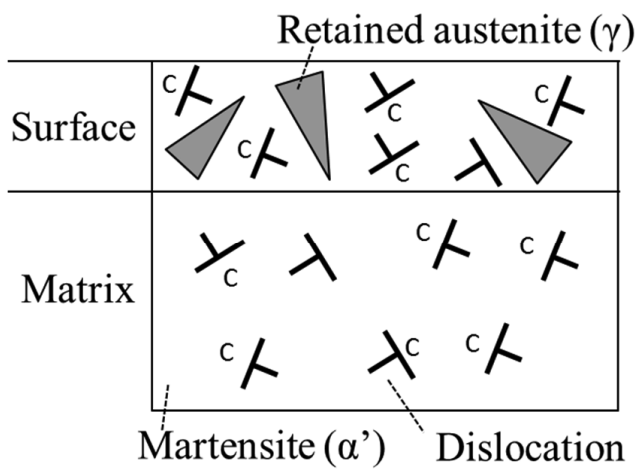

(a) Before test

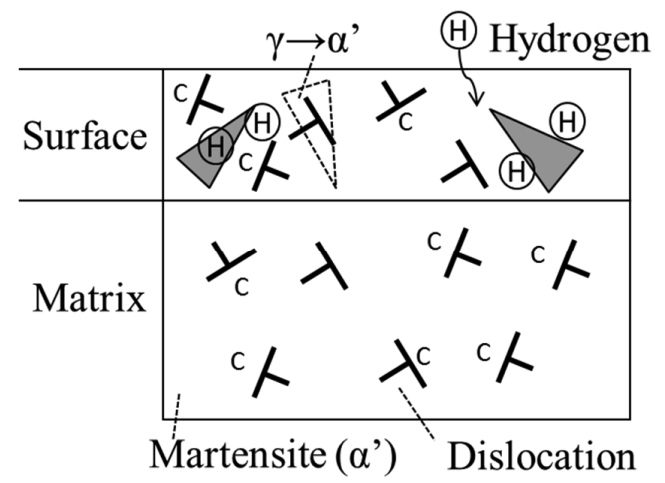

(b) After $2 \times 10^{7}$ cycles

Fig. 10. Schematic illustrations of the hydrogen trapping behavior by retained austenite in rolling contact fatigue. 
ness. The activation energy of hydrogen desorption (Ea) of these specimens were then obtained by the same method as the specimens $\mathrm{A}$ and $\mathrm{B}$. The volume fraction of retained austenite was $10.9 \%$ for the non-subzero-treated specimen and $6.0 \%$ for the subzero-treated specimen. These specimens were regarded as the specimens A and B in this study before the rolling contact fatigue test. They were cathodic charged with hydrogen in a $30 \mathrm{~g} \cdot \mathrm{L}^{-1} \mathrm{NH}_{4} \mathrm{SCN}$ solution at a current density of $2 \mathrm{~A} \cdot \mathrm{m}^{-2}$ for 48 hours and subjected to
TDA by varying the heating rate. The absorbed hydrogen concentration was 10.1 mass ppm for the non-subzerotreated specimen with (10.9\% retained austenite specimen) and 7.90 mass ppm for the subzero-treated specimen $(6.0 \%$ retained austenite specimen). The TDA profiles of hydrogen measured by varying the heating rate are shown in Fig. 13, and the relationship between $\ln \left(\Phi / \mathrm{T}_{\mathrm{C}}{ }^{2}\right)$ and $\mathrm{T}_{\mathrm{C}}{ }^{-1}$ and is shown in Fig. 14. The Ea was $36.2 \mathrm{~kJ} \cdot \mathrm{mol}^{-1}$ for the $10.9 \%$ retained austenite specimen and $42.2 \mathrm{~kJ} \cdot \mathrm{mol}^{-1}$ for the $6.0 \%$

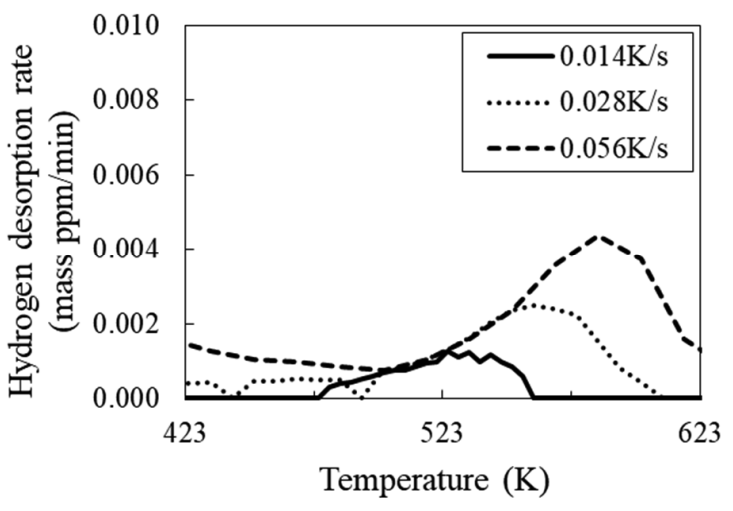

(a) Specimen A

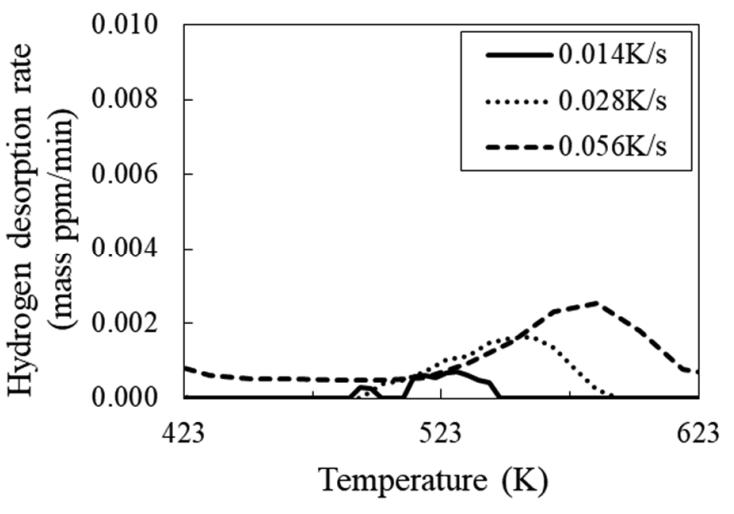

(b) Specimen B

Fig. 11. TDA profiles of hydrogen at three different heating rates after $2 \times 10^{7}$ cycles of the rolling contact fatigue test.

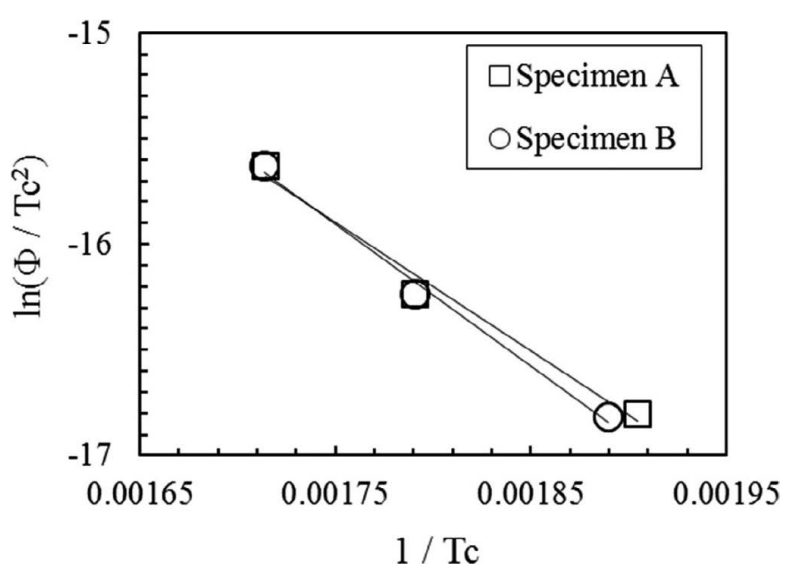

Fig. 12. Relationship between $\ln \left(\Phi / \mathrm{Tc}^{2}\right)$ and $1 / \mathrm{T}_{\mathrm{c}}$ after $2 \times 10^{7}$ cycles of the rolling contact fatigue test.

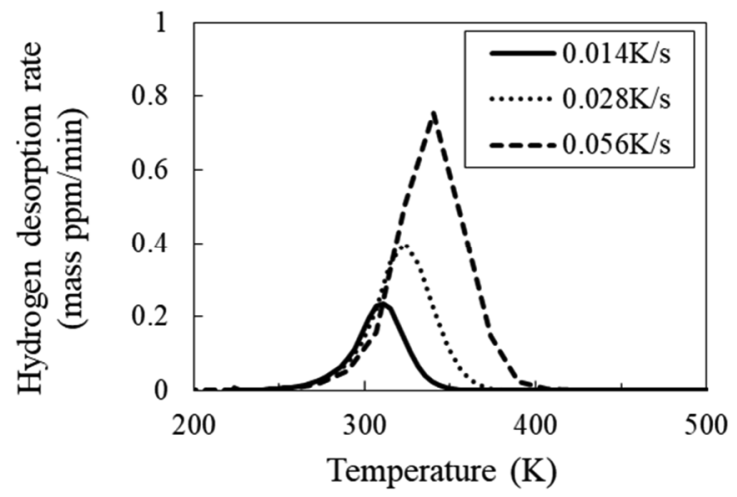

(a) $10.9 \%$ retained austenite

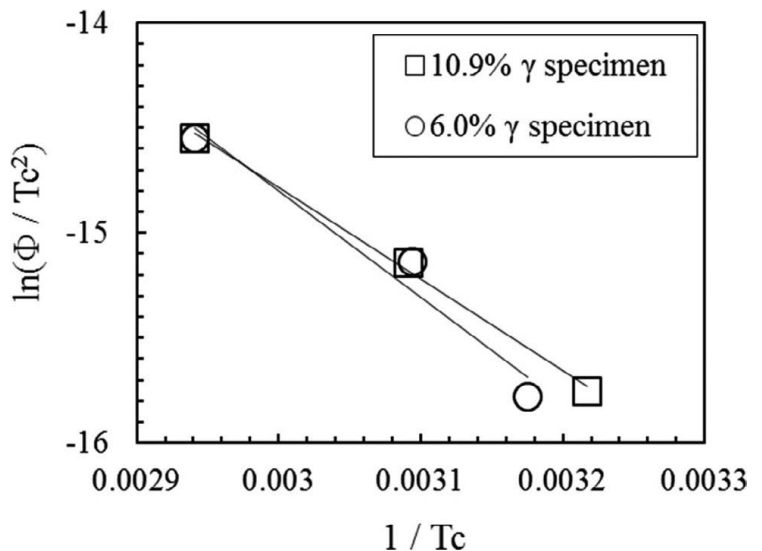

Fig. 14. Relationship between $\ln \left(\Phi / \mathrm{Tc}^{2}\right)$ and $1 / \mathrm{T}_{\mathrm{c}}$ in $0.8 \% \mathrm{C}$ steels.

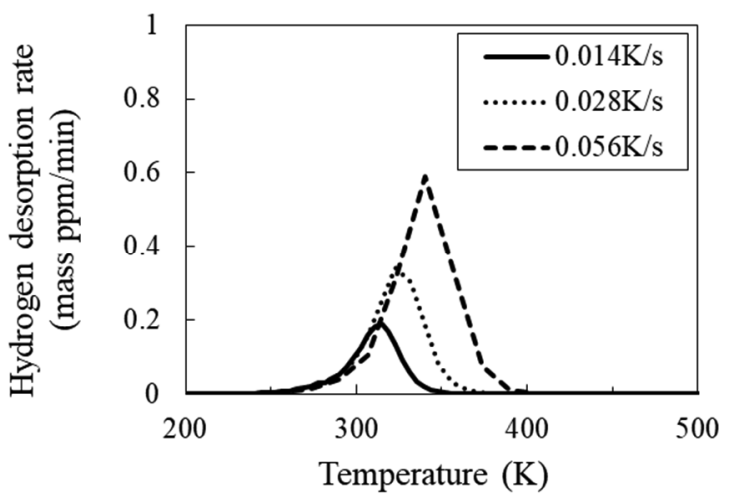

(b) $6.0 \%$ retained austenite

Fig. 13. TDA profiles of hydrogen of $0.8 \% \mathrm{C}$ steels at three different heating rates. 
Table 2. Hydrogen trapping behavior and microstructural changes in rolling contact fatigue. The value of the activation energy before the test is the result of $0.8 \% \mathrm{C}$ steel.

\begin{tabular}{ccccc}
\hline & \multicolumn{2}{c}{ Specimen A } & \multicolumn{2}{c}{ Specimen B } \\
\cline { 2 - 5 } & $\begin{array}{c}\text { Before } \\
\text { the Test }\end{array}$ & $\begin{array}{c}\text { After } 2 \times 10^{7} \\
\text { Test Cycles }\end{array}$ & $\begin{array}{c}\text { Before } \\
\text { the Test }\end{array}$ & $\begin{array}{c}\text { After } 2 \times 10^{7} \\
\text { Test Cycles }\end{array}$ \\
\hline $\begin{array}{c}\text { Retained } \\
\text { Austenine (\%) }\end{array}$ & 10.4 & 6.4 & 4.9 & 4.0 \\
$\begin{array}{c}\text { Dislocation Density } \\
\left(\mathrm{m}^{-2}\right)\end{array}$ & $1.7 \times 10^{16}$ & $9 \times 10^{15}$ & $1.5 \times 10^{16}$ & $7 \times 10^{15}$ \\
$\begin{array}{c}\text { Absorbed Hydrogen } \\
\text { Concentration at } \\
\text { the Second Peak } \\
(\text { mass ppm) }\end{array}$ & 0 & 0.14 & 0 & 0.08 \\
$\begin{array}{c}\text { Activation Energy } \\
\left(\mathrm{kJ} \cdot \mathrm{mol}^{-1}\right)\end{array}$ & $\mathrm{N} / \mathrm{A}$ & 50.6 & $\mathrm{~N} / \mathrm{A}$ & 55.8 \\
\hline
\end{tabular}

retained austenite specimen.

The Ea calculated for the $0.8 \% \mathrm{C}$ steel was close to that reported by Sekine et al. ${ }^{23)}$ for a dual-phase steel composed of martensite and $10 \%$ retained austenite. The Ea of the $0.8 \% \mathrm{C}$ steels, which simulate the state before rolling contact fatigue test of the specimens $\mathrm{A}$ and $\mathrm{B}$, was higher for the steel with the lower volume fraction of retained austenite. This tendency is similar with the specimens A and B specimens after the fatigue test. Furthermore, the Ea of the $0.8 \%$ $\mathrm{C}$ steel was lower than that after the test. Based on the above results, the hydrogen trapping behavior and microstructural changes in rolling contact fatigue in the present study is summarized in Table 2. In this study, it was presumed that the absorbed hydrogen is trapped in retained austenite. However, the Ea values after the rolling contact fatigue test were higher than the reported ones due to austenite, and were higher than the Ea values of the $0.8 \% \mathrm{C}$ steel specimens in this study. These results suggest that the absorbed hydrogen during the rolling contact fatigue would be trapped in more stable trapping sites relating to the retained austenite, which were formed under cyclic stressing by contact fatigue.

\section{Conclusions}

The hydrogen absorption behavior and microstructural changes in the rolling contact fatigue process were investigated by using the carburized SCr420 steel with the different volume fractions of retained austenite controlled by the subzero treatment. Following findings are obtained from the results:

(1) The volume fraction of retained austenite decreased with increasing number of cycles, because the martensite transformation of the retained austenite would proceed under rolling contact stress.

(2) The TEM observations showed that the dislocations were uniformly distributed at a high density before the rolling contact fatigue test. After the fatigue test, regions where the dislocations were distributed with high density in the same way as before the test and regions where dislocation cell structures were formed were observed. The dislocation density totally decreased after the fatigue test.

(3) Hydrogen analysis using the TDA method con- firmed hydrogen desorption at the second peak between 423 and $623 \mathrm{~K}$ only after the rolling contact fatigue test. The second-peak hydrogen could be regarded as absorbed hydrogen into the specimen during the rolling contact fatigue test because only the second-peak hydrogen concentration increased with an increasing number of cycles in the test. Absorbed hydrogen concentration was lower in the specimen, which reduced the initial volume fraction of retained austenite by subzero treatment.

(4) The second-peak hydrogen concentration depended on the volume fraction of retained austenite before the rolling contact fatigue test, and increased also when the introduction of new dislocations due to the martensite transformation of retained austenite was considered to be small. Given these results, the trapping sites for the hydrogen absorbed during the rolling contact fatigue test are mainly thought to have caused by retained austenite.

(5) The activation energy of hydrogen desorption obtained using the Choo-Lee method after the rolling contact fatigue test was $50.6 \mathrm{~kJ} \cdot \mathrm{mol}^{-1}$ for the non-subzerotreated specimen (with $10.4 \%$ retained austenite) and 55.8 $\mathrm{kJ} \cdot \mathrm{mol}^{-1}$ for the subzero-treated specimen (with $4.9 \%$ retained austenite). The activation energy of hydrogen desorption was higher after the fatigue test than before the fatigue test. This suggests that cyclic stressing formed more stable hydrogen trapping sites than no stressing, and that hydrogen was trapped at these sites.

\section{REFERENCES}

1) T. Fujimatsu: 235th and 236th Nishiyama Memorial Seminar, ISIJ, Tokyo, (2018), 64 (in Japanese).

2) K. Tamada and H. Tanaka: Wear, 199 (1996), 245.

3) H. Harada, T. Mikami, M. Shibata, D. Sokai, A. Yamamoto and H. Tsubakino: ISIJ Int., 45 (2005), 1897.

4) Y. J. Li, M. Herbig, S. Goto and D. Raabe: Mater. Charact., 123 (2017), 349.

5) S. W. Ooi, A. Gola, R. H. Vegter, P. Yan and K. Stadler: Mater. Sci. Technol., 33 (2017), 1657.

6) H. Harada, N. Oguma, A. Yamamoto and H. Tsubakino: Tetsu-toHagané, 89 (2003), 789 (in Japanese).

7) A. Muroga and H. Saka: Tetsu-to-Hagané, 84 (1998), 351 (in Japanese).

8) K. Hiraoka: Tetsu-to-Hagané, 94 (2008), 636 (in Japanese).

9) H. Uyama, H. Yamada, H. Hidaka and N. Mitamura: Tribol. Online, 6 (2011), 123.

10) H. Uyama: J. Jpn. Soc. Tribol., 60 (2015), 658 (in Japanese)

11) T. Kinami: Denki Seiko (Electr. Furn. Steel), 84 (2013), 55 (in Japanese).

12) K. Hiraoka, T. Fujimatsu, N. Tsunekage and A. Yamamoto: J. Jpn. Soc. Tribol., 52 (2007), 888 (in Japanese).

13) T. Ungár and A. Borbély: Appl. Phys. Lett., 69 (1996), 3173.

14) K. Takai, G. Yamauchi, M. Nakamura and M. Nagumo: J. Jpn. Inst. Met., 62 (1998), 267 (in Japanese).

15) D. Hirakami, S. Yamasaki, T. Tarui and K. Ushioda: Tetsu-toHagané, 100 (2014), 1322 (in Japanese).

16) T. Nagase, T. Ito, Y. Nishimura, H. Suzuki and K. Takai: Tetsu-toHagané, 102 (2016), 534 (in Japanese).

17) E. Sakurada, S. Hiwatashi and K. Ushioda: J. Jpn. Inst. Met., 80 (2016), 655 (in Japanese).

18) R. C. Dommarco, K. J. Kozaczek, P. C. Bastias, G. T. Hahn and C. A. Rubin: Wear, 257 (2004), 1081.

19) S. Taketomi, R. Matsumoto and N. Miyazaki: Acta Mater., 56 (2008), 3761.

20) E. Clouet, S. Garruchet, H. Nguyen, M. Perez and C. S. Becquart: Acta Mater., 56 (2008), 3450.

21) K. Takai, K. Murakami, N. Yabe, H. Suzuki and Y. Hagihara: J. Jpn. Inst. Met., 72 (2008), 448 (in Japanese).

22) W. Y. Choo and J. Y. Lee: Metall. Trans. A, 13 (1982), 135.

$23)$ D. Sekine, K. Takai, Y. Sakiyama, T. Ohmura and K. Ebihara: CAMP-ISIJ, 31 (2018), 798, CD-ROM (in Japanese). 